\title{
Los derechos de los contribuyentes en los acuerdos de intercambio de información suscritos por Colombia*
}

\section{The taxpayers' rights in the tax information exchange agreements signed by Colombia}

\section{Tatiana González Henao ${ }^{1}$}

\section{Resumen}

En la última década se han logrado avances significativos en materia de intercambio internacional de información tributaria, comenzando con las modificaciones introducidas al artículo 26 del modelo de convenio de la OCDE, continuando con la amplia red de acuerdos bilaterales de intercambio de información tributaria suscritos por los diferentes Estados para llegar, finalmente, a un acuerdo multilateral basado en el estándar internacional para la transparencia fiscal. Por su parte, Colombia ha adoptado una función activa en el intercambio internacional de información tributaria, pero desafortunadamente las garantías constitucionales de los contribuyentes en el marco de acuerdos de información tributaria no han tenido la misma prevalencia en la agenda política del Gobierno. La presente investigación se centró en analizar si los acuerdos suscritos por Colombia habían sido celebrados en cumplimiento de los principios constitucionales o si, por otra par- te, se podían identificar algunas violaciones de normas constitucionales para efectos de mostrar la necesidad de incorporar mecanismos efectivos de protección de los derechos de los contribuyentes y la regulación del secreto tributario.

Palabras clave: derechos de los contribuyentes, secreto tributario, acuerdos internacionales de intercambio de información tributaria, transparencia fiscal internacional, confidencialidad.

\begin{abstract}
In the last decade, significant advances have been made in the field of international tax information exchange, beginning with the modifications made to the article 26 of the OECD model convention, continuing with the large network of bilateral tax information exchange agreements signed by the different States to finally reach a multilateral agreement based on the global tax transparency
\end{abstract}

\footnotetext{
* DOI: https://doi.org/10.18601/16926722.n10.10

${ }^{1}$ Abogada, especialista en Legislación Tributaria de la Universidad Pontificia Bolivariana y magíster en Derecho con énfasis en Tributación de la Universidad Externado de Colombia. Docente en la Especialización en Legislación Tributaria de la Universidad Pontificia Bolivariana y asesora tributaria en la firma Visión Legal S.A.S. Correo electrónico: tgonzalezh@ visionlegal.com.co
} 
standard. Meanwhile, Colombia has adopted an active role in the tax international information exchange, but unfortunately the taxpayers' constitutional guarantees in the framework of tax information agreements hadn't have the same prevalence in the politic agenda of the government. The Present investigation was focused on analyzing if the tax information exchange agreements signed by Colombia had been concluded in compliance with the Constitutional principles or if, In the other hand, some violations of constitutional rules could be identified, in order to demonstrate the need to incorporate effective mechanisms of protection of taxpayers' rights and tax secrecy regulation.

Key Words: taxpayers' rights, tax secrecy, tax international information exchange agreements, global tax transparency, confidentiality.

\section{Sumario}

Introducción. I. El intercambio internacional de información frente a la Constitución Política de Colombia. II. Fundamento y límites a la suscripción en AIIT. A. Deber de reserva y uso de la información tributaria obtenida a través de procedimientos de intercambio. B. Derecho a la intimidad. C. Derecho de defensa y contradicción en desarrollo del derecho fundamental al debido proceso. D. El secreto tributario y su falta de desarrollo legislativo en Colombia. Conclusiones. Referencias.

\section{Tabla de abreviaturas}

CDI Convenios para Evitar la Doble
Imposición
AIIT Acuerdos para el Intercambio
de Información Tributaria

DIAN Dirección de Impuestos y Aduanas Nacionales

OCDE Organización para la Cooperación y el Desarrollo Económico

\section{Introducción}

En la actualidad, en el ámbito mundial se ha logrado un consenso internacional por la transparencia fiscal, en el que gobiernos alrededor del mundo son partícipes activos, incentivados principalmente por las deficiencias detectadas en sus sistemas tributarios internos y por la necesidad de obtener información sobre las operaciones transnacionales que realicen sus contribuyentes, a efectos de lograr incrementar el recaudo de sus tributos y fortalecer la lucha contra la evasión y el fraude fiscal.

Dicho consenso ha tenido una evolución notable en la última década, producto de la competencia fiscal perniciosa entre Estados, desatada con el fenómeno de la globalización que, como lo menciona Marulanda (2013), bajo la autonomía de la potestad tributaria, le ha permitido a algunos Estados encontrar sus ventajas competitivas en ofrecer una mayor rentabilidad fiscal a las inversiones extranjeras móviles acompañadas, en muchas ocasiones, de un alto grado de opacidad.

Es así como la imperante necesidad de obtener información tributaria internacional se ha consolidado no solo en la agenda política internacional sino también en la local y Colombia no ha sido la excepción, adoptando en los últimos años una función activa en la suscripción de tratados internacionales, al amparo de los cuales se ha pactado el intercambio de información a solicitud, espontáneo o automático, donde este último ha tenido una función primordial, tanto en los 
avances como en los acuerdos bilaterales como multilaterales, contando en la actualidad con nueve Convenios para Evitar la Doble Imposición (CDI) vigentes, tres Acuerdos para el Intercambio de Información Tributaria (AIIT) de los cuales solo el suscrito con Estados Unidos se encuentra vigente y fue desarrollado por el Acuerdo Intergubernamental para mejorar el cumplimiento fiscal internacional e implementar el intercambio automático de información respecto de la Ley sobre el Cumplimiento fiscal relativo a cuentas en el extranjero (IGA FATCA), seguido por la Convención de Asistencia Administrativa Mutua en Materia Tributaria (CAAMMT) (OCDE, 2011).

No obstante, pese a los importantes acercamientos entre los diferentes Estados, es preciso advertir que la protección de los derechos de los contribuyentes, en el marco de estos acuerdos, no ha contado con la misma dedicación por parte de los negociadores y es precisamente esta situación la que ha dado origen a la problemática abordada en esta investigación, pues ante el acelerado crecimiento del número de tratados adoptados, es pertinente preguntarse si ¿Colombia cuenta con mecanismos efectivos de protección de los derechos fundamentales a la intimidad y al debido proceso de los contribuyentes frente a los acuerdos de intercambio de información tributaria (AIIT) suscritos?

Para responder a este interrogante, los objetivos perseguidos con la presente investigación fueron delimitar el alcance de los AIIT suscritos por Colombia frente a los derechos fundamentales a la intimidad y al debido proceso, determinar si a la luz del estudio realizado es necesario regular el secreto tributario para efectos de lograr una protección efectiva del derecho a la intimidad de los contribuyentes y establecer la convenien- cia de incluir regulaciones concretas en los AIIT para garantizar la participación de los contribuyentes.

Para dar cumplimiento a los objetivos propuestos, la metodología empleada consistió en realizar una revisión de la literatura extranjera sobre el consenso por la transparencia fiscal internacional, el origen de los AIIT así como las condiciones y características de los modelos de tratados internacionales que permiten este intercambio para, posteriormente, analizar la validez y legitimidad de los tratados suscritos por Colombia a la luz de los requisitos formales establecidos en la Constitución y del principio de reciprocidad.

\section{El intercambio internacional de información frente a la constitución política de Colombia}

Este primer análisis se convierte en un escenario óptimo para plantear algunas problemáticas derivadas de la evidente contraposición que existe entre los intereses del Estado y de sus contribuyentes partiendo, para estos efectos, del concepto de legitimidad adoptado por Bodansky (1999), entendido como la manifestación del consentimiento del Estado otorgado por la norma superior y como el poder que tiene la legislatura para crear reglas legales. Asimismo como lo menciona Mosquera (2016), desde la perspectiva tributaria internacional, el concepto de legitimidad busca que las normas adoptadas tengan que cumplirse por la comunidad, pero que además sean aceptadas y cumplidas voluntariamente, comprendiendo además una conexión con la participación y representación de los contribuyentes en el proceso decisorio.

Bajo este concepto de legitimidad, es pertinente analizar el hecho de que en los AIIT, 
al tener la naturaleza de tratados internacionales, si bien deben ser sometidos a aprobación del Congreso y a estudio previo del Juez Constitucional, las funciones del órgano de representación popular se encuentran limitadas, toda vez que por expresa disposición legal, en el caso colombiano, no le es permitido al Congreso la enmienda de estos, toda vez que "la enmienda no puede ser sino el fruto de la voluntad de las partes contratantes" (Sentencia C-227 de 1993, p. 8).

Ahora bien, frente a la manifestación del Consentimiento del Estado, existen unos elementos constitucionales cuya presencia es un requisito exigido para predicar la legitimidad de los tratados internacionales, como lo es el principio de reciprocidad. Este principio ha tenido un importante desarrollo en materia de intercambio de información tributaria, a raíz del creciente interés de los diferentes Estados en el suministro recíproco de información.

Es así como la Organización para la Cooperación y Desarrollo Económicos (OECD, 2006), en el caso específico de intercambio de información, precisó que la reciprocidad consiste en que la información que un Estado está obligado a obtener y proveer es la información que la parte requirente podría, a su vez, recabar bajo su legislación interna. Aclarando que la realización material del principio de reciprocidad lleva a que los Estados contratantes no puedan usufructuarse de un sistema de información más amplio y más completo que su propio sistema. Por su parte, Pastrana (2005) manifiesta que la reciprocidad debe ser entendida como el intercambio de conductas se realiza en sentido material si dichas conductas están condicionadas al otorgamiento mutuo de ventajas equivalentes o idéntica.
En este sentido, la realización del principio de reciprocidad busca evitar imponer a un Estado contratante más cargas de las que el otro Estado está en la posibilidad de cumplir, así como evitar un desequilibrio en la generación de beneficios; sin embargo y como fue objeto de análisis en esta investigación, no pareciera existir coherencia entre el límite al intercambio de información consistente en que un Estado contratante no esté obligado a suministrar información que no se pueda obtener en aplicación de su legislación interna o de su práctica administrativa normal o la del otro Estado contratante, y la obligación que tiene el Estado requerido de recabar información solicitada, aún en el evento en que no sea de interés nacional para fines tributarios.

En el caso de los AIIT suscritos por Colombia, se procedió a analizar si se cumple el principio de reciprocidad, por una parte, en los compromisos asumidos con Barbados y Emiratos Árabes Unidos y, por la otra, en los asumidos con Estados Unidos incluyendo su respectivo acuerdo intergubernamental, llegando a la conclusión preliminar de que, mientras en los AIIT suscritos con los dos primeros países se establecen límites tendientes a garantizar la realización del principio de reciprocidad en sentido material, prescribiendo que la parte contratante no estará obligada a tomar medidas administrativas distintas a las previstas en su legislación o en su procedimiento interno, al remitirse al AIIT suscrito entre Colombia y Estados Unidos la conclusión es diametralmente opuesta como se pasa a explicar.

Si bien es cierto que en el análisis previo de constitucionalidad del AIIT suscrito con Estados Unidos, declarado exequible por la Corte Constitucional (Sentencia C-225 de 2014), decisión que constitucionalmente 
tiene el carácter de definitiva, esa corporación consideró que este tratado cumple el principio de reciprocidad por consagrar los mismos derechos y obligaciones de los Estados contratantes, al analizar detenidamente el contenido del numeral 4 del artículo 4 de dicho acuerdo surgen algunos interrogantes ya que establece que si el Estado requerido no puede obtener la información solicitada en sus archivos fiscales, deberá adoptar todas las medidas, incluidas las de carácter coercitivo, para facilitar al Estado requirente la información solicitada, en el entendido de que si bien la sola disposición no genera un desequilibrio en la relación contractual de los Estados, el mismo podría derivarse de las cargas administrativas y económicas adicionales que deba suplir el Estado requerido para cumplir con dicha obligación.

La situación descrita cobra especial relevancia al analizar el texto del IGA FATCA, no solo atendiendo al hecho de que a la fecha de elaboración de la presente investigación, Estados Unidos no envía información a Colombia debido a que el sistema de tratamiento de datos colombiano no cumple con las especificaciones y requerimiento técnicos de seguridad exigidos, a pesar de que Colombia empezó a transmitir la información acordada desde el 2015, sino también al hecho de que los compromisos asumidos por Colombia han implicado cuantiosas modificaciones a los sistemas informáticos para recabar información así como cambios en la normatividad vigente, desbordando además las cargas administrativas en cabeza tanto de la autoridad tributaria como de las entidades financieras particulares.

Adicionalmente, es necesario advertir el desequilibrio que surge de la información que Colombia se obliga a transmitir frente a la que Estados Unidos se obliga a reportar a Colombia, en especial en lo establecido en los literales a) y b) del numeral del artículo 2 del IGA FATCA, donde las cuentas reportables a Estados Unidos se definen como cuenta financiera mantenida en una institución financiera "con una o más Personas que ejercen el Control que sean Personas Especificadas de EE.UU" (DIAN, Resolución 000060 de 2015, art. 1, p. 7), entendiendo por "Persona de Estados Unidos" a los ciudadanos de Estados Unidos o las personas naturales residentes de Estados Unidos, entre otros.

Definiendo a su vez como "personas que ejerce el control" las personas naturales que ejercen control sobre una entidad, estableciendo que el término "accionista de Estados Unidos" significa, con respecto a cualquier corporación colombiana, una persona de Estados Unidos que posee o se considera poseedor del $10 \%$ o más del total del poder de votos combinado con todos los tipos de acciones con derecho a voto, o con más del 10\% del capital (DIAN, Resolución 000060 de 2015, anexo II).

Por otra parte, según la definición de “cuenta reportable a Colombia" se advierte que en relación con las cuentas de depósito, Estados Unidos solo estará obligado a reportarlas cuando sean mantenidas por una persona natural residente en Colombia y se paguen intereses y/o dividendos cuyo valor exceda de $\$ 10$ anuales y, en relación con las cuentas financieras distintas a cuentas de depósito, éstas solo serán reportables cuando el Cuentahabiente sea un residente de Colombia, sin que para dicho efecto pueda tratarse como Cuentahabiente a la persona que mantenga una cuenta financiera en beneficio o por cuenta de otra persona en su calidad de agente, custodio, representante, firmante, asesor de inversiones o intermediario, y esta 
otra persona es titular de la cuenta (DIAN, Resolución 000060 de 2015).

Así las cosas, el desequilibrio surge de que, mientras Colombia se obliga a entregar información sobre cuentas financieras mantenidas en instituciones financieras colombianas cuyo titular sea una persona natural ciudadana o residente en Estados Unidos y/o de las sociedades cuyos accionistas que sean personas especificadas de Estados Unidos posean más del 10\% de las acciones y se establece que deberán considerarse cuentas reportables a Estados Unidos aquellas en las que, por ejemplo, se conozca una dirección para recibir correspondencia, un número telefónico o poder de representación legal a persona con dirección en Estados Unidos, entre otros, Estados Unidos, por su parte, no estará obligado a realizar una debida diligencia tan estricta y en relación con el representante, firmante, asesor de inversiones o intermediario Colombiano, esto no dará la calidad de cuenta reportable a Colombia.

La situación descrita permite evidenciar la falta de reciprocidad en sentido material en el IGA FATCA, toda vez que, no son equivalente las cargas administrativas para recabar la información tributaria requerida, ni tampoco los compromisos asumidos por Colombia en relación con la información reportable a Estados Unidos.

Desde otra perspectiva, en relación con principio de legalidad frente al IGA FATCA, surgen algunos interrogantes, en especial en lo referido a las remisiones que dicho acuerdo realiza al Código de Rentas Internas de Estados Unidos y que, en última instancia, son las que delimitan el alcance del deber de información masivo establecido en la legislación colombiana así como el supuesto jurídico del cual pudiere llegar a derivarse una eventual sanción por información incompleta o errónea.

En este sentido, la Corte Constitucional (Sentencia C-690 de 2003) advierte que, si bien las regulaciones sobre el deber de informar no se encuentran en el ámbito de reserva estricta del principio de legalidad, corresponde a la ley establecer la base de las obligaciones formales en materia tributaria. Bajo este planteamiento, atendiendo a que solo hasta la expedición de la Ley 1819 de 2016 el legislador se ocupó de regular de manera específica las obligaciones relacionadas con el intercambio de información, resulta bastante cuestionable que la DIAN vía Resolución hubiere pretendido la aplicación de la sanción por no informar establecida en el artículo 651 del Estatuto Tributario, sin existir una remisión legal expresa.

Por otra parte, como otro elemento de validez de los AIIT suscritos por Colombia se analizó si puede el Presidente de la República delegar la facultada para suscribir dichos tratados, así como los acuerdos intergubernamentales, partiendo del concepto de delegación adoptado por la Corte Constitucional (Sentencia C-693 de 1998) como una técnica de manejo administrativo de las competencias que autoriza la Constitución de manera general o específica, autorización que de conformidad con lo establecido en el artículo 211 de la Constitución Política deberá estar contenida en la Ley.

En el caso de los tratados internacionales, según lo consagrado en el numeral 2 del artículo 189 de la Constitución Política de Colombia, la competencia para su celebración y para dirigir las relaciones internacionales fue conferida constitucionalmente al presidente de la República, que, como se mencionó anteriormente, solo puede manifestar el consentimiento del Estado con la aprobación 
del Congreso y la revisión previa de la Corte Constitucional.

Ahora bien, en cuanto a la posibilidad de delegar dicha facultad, es pertinente indicar que salvo lo establecido en la Convención de Viena (Ley 406 de 1997) que reconoce como representantes del Estado a los jefes de Estado, jefes de gobierno y ministros de Relaciones Exteriores, no existe autorización legal que permita al presidente delegar en otros funcionarios la facultad de celebrar tratados internacionales, razón por la cual es pertinente preguntarse si ¿los AIIT suscritos por Colombia que, en el caso de Barbados y Emiratos Árabes Unidos fueron concluidos por el ministro de Hacienda y en el caso de Estados Unidos fue suscrito por el entonces director general de Impuestos y Aduanas Nacionales (DIAN), gozan de legitimidad?

Lo anterior, porque aunque la Corte Constitucional, en ejercicio del control previo de constitucionalidad ${ }^{2}$ del AIIT suscrito con Estados Unidos (Sentencia C-225 de 2014), reconoció que el director general de la DIAN no se encuentra dentro de catálogo de servidores públicos frente a los cuales el Convenio de Viena presume la representación del Estado, resolvió la exequibilidad de dicho tratado con fundamento en los plenos poderes conferidos por parte del ministro de Relaciones Exteriores para la suscripción de este, situación frente a la cual surge la pregunta de si al tratarse de una facultad constitucionalmente otorgada al presidente de la república, era este quien debía otorgar los plenos poderes y no el Ministro de Relaciones Exteriores.

En el mismo orden de ideas, al analizar el IGA FATCA se tiene que aunque los pronunciamientos de la Corte Constitucional han sido pacíficos en sostener que cuando se trate de un instrumento internacional que no genera nuevas obligaciones para Colombia, puede prescindirse del trámite de aprobación parlamentaria y ponerse en vigor por el presidente de la república, en ejercicio de la competencia que posee para la dirección de las relaciones internacionales, no deja de llamar la atención el hecho de que el IGA FATCA haya sido acordado por la autoridad competente definida en el AIIT en aplicación el artículo 211 de la Constitución Política y no por el presidente de la República, toda vez que a pesar de tratarse del desarrollo directo de un tratado internacional, no deja de ser un instrumento internacional cuya competencia originaria está conferida al presidente de la república.

La anterior observación se fundamenta en que, como lo ha reiterado la Corte, la facultad constitucional está radicada en el presidente de la república, por lo que es pertinente cuestionar si al tener el AITT la categoría de Ley puede entenderse válidamente delegada, a pesar de que en materia de tratados internacionales no le está

\footnotetext{
${ }^{2}$ Constitución Política. Artículo 241. "A la Corte Constitucional se le confía la guarda de la integridad y supremacía de la Constitución, en los estrictos y precisos términos de este artículo. Con tal fin, cumplirá las siguientes funciones: [...]

10. Decidir definitivamente sobre la exequibilidad de los tratados internacionales y de las leyes que los aprueben. Con tal fin, el Gobierno los remitirá a la Corte, dentro de los seis días siguientes a la sanción de la ley. Cualquier ciudadano podrá intervenir para defender o impugnar su constitucionalidad. Si la Corte los declara constitucionales, el Gobierno podrá efectuar el canje de notas; en caso contrario no serán ratificados. Cuando una o varias normas de un tratado multilateral sean declaradas inexequibles por la Corte Constitucional, el Presidente de la República sólo podrá manifestar el consentimiento formulando la correspondiente reserva".
} 
dado al Congreso de la república realizar enmiendas, en especial si se observa que en los informes publicados en las Gacetas del Congreso n. $355,359,416$ y 442 del 2013 , no hubo discusión alguna sobre dicha delegación y que, aún si se tratara del ejercicio de la potestad reglamentaria, la misma también fue constitucionalmente conferida al Presidente de la República (Constitución Política de Colombia, art. 189).

\section{Fundamento y límites a la suscripción de AIIT}

Para el desarrollo de los objetivos planteados, en la investigación adelantada se procedió a identificar el fundamento y los límites al intercambio de información, haciendo especial referencia al deber de reserva y uso de la información, al derecho a la intimidad, al derecho de defensa y contradicción como desarrollo del derecho al debido proceso y al secreto tributario, con el fin de determinar si a la luz de los principios que fundamentan el Estado social de derecho, se legitima la prevalencia del deber de contribuir frente a los derechos fundamentales de los contribuyentes, o si se debe revaluar dicha prevalencia y concentrar esfuerzos en la consagración de mecanismos que garanticen los derechos a la intimidad y al debido proceso de los contribuyentes.

Tal como lo manifiestan Del Prado Merino y Nocete (2011), el deber constitucional de contribuir con los gastos públicos ha sido reconocido como el fundamento para imponer al contribuyente las obligaciones de colaboración, así como el deber de entregar información para hacer efectiva la obligación de contribuir. No obstante, advierte Calderón (2012) que, en el marco de un acuerdo de intercambio de información, el obligado tributario que debe colaborar con las autoridades de su Estado, aportando la información requerida, a pesar de que tal procedimiento no persigue tutelar el deber de contribuir al sostenimiento de los gastos públicos a la Hacienda de tal Estado, sino que la información tiene trascendencia fiscal solo para el Estado requirente.

En Colombia, la Corte Constitucional ha afirmado que el deber de contribuir a financiar los gastos y las inversiones del Estado, involucra tanto obligaciones sustanciales como obligaciones formales. Encontrándose en el primer grupo la obligación de pagar los tributos y en el segundo la obligación de cumplir con "aquellas cargas que facilitan la función fiscal de la administración”, como es, por ejemplo, la de "suministrar de manera veraz y oportuna la información necesaria para determinar de manera correcta el monto en el que cada contribuyente está obligado a tributar" (Sentencia C-833 de 2013, p. 43).

Al respecto, al margen de que la suscripción de AIIT, en principio, no parezca fundamentarse en el nacimiento de un vínculo jurídico tributario claro y exigible por parte del Estado requirente de la información frente al contribuyente obligado a suministrarla, ni que tampoco pueda predicarse un aplicación directa del deber constitucional de contribuir con las cargas públicas como si puede predicarse de los derechos fundamentales, lo cierto es que estos acuerdos se han convertido en un mecanismo idóneo para conocer información de las transacciones realizadas fuera del territorio nacional que, de otra manera, los Estados no tendrían posibilidad de conocer, situación que evidentemente se traduce en una alta aceptación estos instrumentos internacionales y en la necesidad de crear herramientas legales que 
permitan garantizar la debida protección de los derechos fundamentales.

Desde otra perspectiva, se encuentran los límites al intercambio de información que han tenido un importante desarrollo en el Convenio para evitar la Doble Imposición Modelo OCDE (MC OCDE), donde en la cláusula 26 se establece que en ningún caso puede obligarse a un Estado a adoptar medidas administrativas contrarias a su legislación o práctica administrativa, ni a las del otro Estado contratante, ni a suministrar información que no se pueda obtener sobre la base de su propia legislación o en ejercicio de su práctica administrativa normal, ni a suministrar información que revele secretos comerciales, gerenciales, industriales o profesionales, procedimientos comerciales o informaciones cuya comunicación sea contraria al orden público (OCDE, 2010).

A su vez, es necesario referirse a los límites que implicaban un obstáculo para el efectivo intercambio de información tributaria y que por este motivo dejaron de serlo, como es el caso del interés doméstico tributario en recabar la información requerida y el secreto bancario, estableciéndose expresamente en el artículo 26 MC OCDE que los Estados requeridos no pueden rehusarse a recabar y transmitir la información amparados tales límites. Frente a la desaparición de este último límite es pertinente indicar que el mismo denota un quebrantamiento al principio de reciprocidad constitucionalmente exigido como fundamento del intercambio de información.

La anterior apreciación tiene sustento en la Ley Estatutaria 1581 de 2012 que prohíbe la transferencia de datos personales de cualquier tipo a países que no proporcionen niveles adecuados de protección de datos, excluyendo de esta prohibición en el literal d) a las transferencias acordadas en el marco de tratados internacionales en los cuales la República de Colombia sea parte, con fundamento en el principio de reciprocidad; sin embargo partiendo de los compromisos asumidos por Colombia frente al IGA FATCA, atendiendo al hecho de que Estados Unidos aún no entrega información y a la fecha de realización de esta investigación, debido a su legislación no le es posible entregar información sobre saldos de cuentas reportables, es pertinente preguntarse si aún en aquellos eventos en los cuales dicho principio no se desarrolle en sentido material es posible sostener la legítima transferencia de los datos personales, dentro de los cuales se encuentra la información tributaria.

En cuanto al secreto profesional, es necesario indicar que, tal como lo señala Santamaría Pastor (1985), al tener la categoría de límite infranqueable en relación con las potestades inquisitivas de la jurisdicción penal, con mayor razón debe tener estas misma naturaleza frente a las actuaciones que adelante la Administración Tributaria; sin embargo, por una parte, en los comentarios al Modelo de AIIT OCDE (MA OCDE), se ha advirtió la improcedencia de invocarlo en aquellos casos en los que un "abogado actúe como accionista, representante, fiduciario, fideicomitente, consejero de una sociedad $o$ en virtud de un poder notarial de representación para representar a una sociedad en asuntos empresariales" (OECD, 2002, p. 30) y, por otra parte, en los comentarios al MC OCDE se señaló que el mismo no protege la información sobre la identidad de un director o de un beneficiario efectivo de la sociedad.

Pese a las restricciones pretendidas por los comentarios a los distintos modelos de tratados de la OCDE, al analizar el alcance del se- 
creto profesional en Colombia se encuentra que la Corte Constitucional en sus primeros análisis precisó que la Carta Política no dejó margen alguno para que el legislador señale las condiciones en que puede vulnerarse un derecho inviolable, razón por la cual cumplir con los deberes derivados de la realización de dicho derecho no es optativo (C-411 de 1993); sin embargo en pronunciamientos más recientes advirtió que "el hecho de que sea inviolable, no implica que el legislador no pueda, como en todos los derechos, regular su ejercicio y resolver los conflictos que puedan presentarse con otras garantías, siempre y cuando estas limitaciones tengan un fin legítimo, proporcional y razonable" (Sentencia C- 200 de 2012, p. 25).

Ahora bien, partiendo del carácter inviolable que le otorgan tanto la Norma Superior como la Corte Constitucional al secreto profesional, es pertinente indicar que la información protegida bajo el secreto profesional comprende toda aquella que es conocida en razón del ejercicio de la abogacía y que esté destinada a mantenerse oculta a los demás, por lo tanto, comprende la información obtenida en el curso de la defensa en procuración como la relacionada con la asesoría brindada.

Frente al secreto comercial como límite al intercambio de información tributaria, la información financiera y los registros contables no son considerados como secreto comercial, profesional o de otra índole, razón por la cual sólo son considerados secreto comercial los "hechos y circunstancias de una importancia económica considerable y que podrían ser explotados de forma práctica y cuyo uso no autorizado podría conllevar un serio perjuicio" (OCDE, 2010, p. 421).

Al respecto, en la legislación interna colombiana es necesario remitirse a la Decisión
486 de la Comunidad Andina de Naciones (CAN), que en su artículo 260 considera como secreto empresarial cualquier información no divulgada que una persona natural o jurídica posea legítimamente y pueda usar en actividad productiva, industrial o comercial, que tenga un valor comercial por ser secreta y haya sido mantenida secreta por su legítimo poseedor, advirtiendo que se encuentra dentro de esta categoría la información referida a las características de los productos a los métodos o proceso de producción e inclusive a los medios de distribución, comercialización o prestación de servicios.

A pesar de la definición adoptada por Colombia a través de la normatividad supranacional de la CAN, es preciso indicar que respecto de los países con quienes Colombia ha suscrito los respectivos tratados para el intercambio de información, podría cuestionarse su aplicación, situación que deja en evidencia la falta de regulación en el derecho interno y amplifica la preocupación existente respecto de la negociación del acuerdo de intercambio de información denominado informe país por país, toda vez que a pesar de afirmarse que el mismo no afecta secretos empresariales, al revisar la legislación interna se encuentra que no existen normas que garanticen la confidencialidad en dicho acuerdo multilateral. (Cockfield y Macarthur, 2015).

\section{A. Deber de reserva y uso de la información tributaria obtenida a través de procedimientos de intercambio}

Señala el profesor Arrieta (1998) que "los datos que obtenga la administración tributaria en el desempeño de sus funciones no pueden ser cedidos ni comunicados a terce- 
ros salvo que el interesado dé su consentimiento, o salvo que, aún sin darlo, exista una excepción a dicha reserva" (p.41). Señalando además que, entendiendo que el deber de suministrar información por parte del contribuyente no puede interpretarse como un menoscabo de sus garantías mínimas, el deber de informar y los AIIT entre administraciones deben enfocar su atención en estas garantías como una línea de defensa de los derechos del contribuyente.

Para efectos de explicar la línea de defensa de los derechos de los contribuyentes Arrieta (1998) señala como uno de los ejes fundamentales de esta, que la información intercambiada, sea utilizada en torno a los fines para los que fue solicitada, el cual adquiere una mayor importancia con la modificación del artículo 26 del MC OCDE, ya que con ocasión de la revisión realizada en 2012 se adhirió el apartado 2 que establece que un Estado contratante puede utilizar la información recibida para otros fines, siempre que en ambas legislaciones estén permitidos esos otros usos.

No obstante, como visionariamente fue advertido por Arrieta (1998), deben existir restricciones al uso de la información tributaria aportada por el obligado tributario, en especial en los casos de investigaciones de delitos perseguibles de oficio, en desarrollo del derecho constitucional a no autoinculparse.

Analizando la legislación colombiana, el artículo 583 del Estatuto Tributario autoriza expresamente que en los procesos penales se suministre copia de las declaraciones cuando sea decretada como prueba por la autoridad competente, y pese a que dicha norma fue declarada exequible por la Corte Constitucional (Sentencia C-489 de 1995) es pertinente indicar que en dicha providencia la discusión estuvo enfocada en la prevalencia del ius puniendi sobre el derecho a la intimidad, pero no se analizó, ni siquiera tangencialmente, el derecho a no declarar contra sí mismo consagrado en el artículo 33 de la Constitución Política que puede vulnerarse a través de la utilización de las declaraciones presentadas por el contribuyente en cumplimiento de un deber formal como una prueba en contra en un proceso penal.

\section{B. Derecho a la intimidad}

En Colombia, aunque el derecho a la intimidad solo tuvo consagración independiente en la Constitución Política de 1991, en la Constitución de 1858 ya existía un reconocimiento a este derecho cuando se establecía que la correspondencia solo podía ser interceptada por autoridad pública con las formalidades prescritas en las leyes, principio que se conservó en las Cartas Políticas de 1863 y 1886.

Para efectos de delimitar este derecho en materia tributaria, la DIAN en la Circular 1 proferida el 14 de enero de 2013, citando la jurisprudencia de la Corte Constitucional ha desarrollado el alcance de este precepto definiendo que dicho derecho se proyecta en dos dimensiones así: "como secreto que impide la divulgación ilegítima de hechos o documentos privados, o como libertad, que se realiza en el derecho de toda persona a tomar las decisiones que conciernen a la esfera de su vida privada" (Sentencia C-489 de 1995, p. 11). Reconociendo además que, con fundamento en la Sentencia T-414 de 1992), en el evento de existir un conflicto insoluble entre el deber de informar y el derecho a la intimidad debe prevalecer este último, como consecuencia de la consagración de la dignidad humada como derecho fundamental y pilar del Estado Social de Derecho; sin embargo, con el pasar 
de los años, la Corte Constitucional ha modificado su posición a efectos de dar una mayor prelación al deber de informar al considerar que la protección de los secretos industriales y el derecho a la intimidad no se vulneran por cederlos a la administración, ya que esta, a su vez, tiene deber de reserva (Collado, Moreno y Carreras, 2012).

Ahora bien, en cuanto al posible choque entre el derecho fundamental a la intimidad y el deber de contribuir, advierte Calderón Carero (2009), que cuando el deber de contribuir requiere de una quiebra o flexibilización del derecho a la intimidad, correlativamente, debe existir la especial protección que proporcionará el ordenamiento a los datos que se ha accedido en virtud de la misma. Afirmando que la prevalencia del deber de contribuir frente al ámbito de lo protegido por el derecho a la intimidad justificará que el uso de lo conocido mediante este procedimiento quede absolutamente reservado a ese fin.

En relación con el derecho fundamental a la intimidad, una vez reconocida la prevalencia que, según la política fiscal adoptada por cada Estado, se le ha conferido al deber de contribuir, es necesario señalar la necesidad de adoptar una carta o declaración de los derechos de los contribuyentes como lo menciona Mosquera (2016), que sea vinculante para los Estados contratantes, que le permita a los contribuyentes verificar y corregir la información objeto del intercambio así como el uso de esta.

\section{Derecho de defensa y contradicción en desarrollo del derecho fundamental al debido proceso}

Ha señalado Oberson (2015) que los derechos de los contribuyentes en materia proce- dimental pueden dividirse en tres categorías: i) el derecho de notificación, ii) derecho a participar en el proceso de recolección de la información, también denominado consulta y iii) derecho a intervenir, advirtiendo que los contribuyentes solo pueden lograr la protección efectiva de sus derechos si están informados del requerimiento antes de que sea transmitida la información a otros Estados; sin embargo, en Colombia no existe desarrollo legal de los derechos de los contribuyentes en materia de intercambio de información tributaria, pues su oportunidad de notificarse e intervenir solo ocurre en el procedimiento de determinación de impuestos, razón por la cual el ejercicio de este derecho en esta etapa inicial se vuelve casi nulo, lo que magnifica la importancia de consagrar en la legislación interna garantías mínimas que garanticen la protección de los derechos fundamentales tendientes a lograr un efectivo intercambio de información en desarrollo de los principios que cimientan Estado Social de Derecho.

Como lo señaló hace algunos años Calderón (2001), en un procedimiento de intercambio de información, los contribuyentes afectados con este, en muchos casos, no cuentan con mecanismos que les permitan controlar el flujo internacional de sus datos, ya que muy pocos países han adoptado regulación que permita ejercer estos derechos, razón por la cual advierte la necesidad de prever mecanismos de control de legalidad de la actuación administrativa adelantada en el marco de un acuerdo de intercambio de información tributaria, bien sea que se trate de un procedimiento de intercambio obligatorio o discrecional, toda vez que no basta el control de legalidad a posteriori, por cuanto este podría presentarse después de haber ocurrido la vulneración de los derechos del contribuyente. 
El anterior análisis tiene su fundamento en que, como acertadamente lo menciona Oberson (2015), en los casos en que los contribuyentes gozan de una extensa protección en la legislación interna del Estado requerido, la ausencia de regulación de los derechos de participación en AIIT, en la mayoría de los casos, no alcanza a generar efectos adversos frente a dichos derechos; sin embargo, Colombia no cuenta con regulación sobre los derechos de los contribuyentes en el marco de estos tratados, razón por la cual la preocupación frente a las garantías constitucionales de los contribuyentes es notable.

En este orden de ideas, bajo el análisis adelantado se evidencia la necesidad de consagrar los derechos de participación de los contribuyentes en el marco de los AIIT, tales como el control de legalidad o impugnación del procedimiento de intercambio de información, tanto en la legislación interna como en el texto dichos tratados, de manera tal que los contribuyentes puedan someter a control de legalidad la actuación administrativa de manera previa a la transmisión de esta, con las respectivas etapas requeridas para el correcto ejercicio del derecho de defensa, en un término que no impida la efectividad de dicho intercambio, pero que permita verificar los motivos que dan origen al intercambio y controlar que en caso de discrecionalidad o incumplimiento de los presupuestos legales, el contribuyente pueda oponerse.

\section{El secreto tributario y su falta de desarrollo legislativo en Colombia}

Atendiendo a la remisión general que en materia de fiscalidad internacional se hace a las normas internas que regulan la protección del secreto tributario y que, dicho derecho, comprende tanto las condiciones de uso y cesión de la información, así como las garantías que el contribuyente puede ejercer en dicho intercambio o de manera previa a este, se evidencia una imperiosa necesidad de que Colombia adopte una regulación que permita lograr una mayor seguridad jurídica y confianza legítima para los contribuyentes, en especial, teniendo en cuenta qué derecho al secreto tributario se ha reconocido, en otras legislaciones, como un mecanismo efectivo de confidencialidad de la información relativa a un determinado contribuyente, quedando prohibida su divulgación, garantizando que dichos datos seguirán disfrutando de un nivel de protección similar cuando sean objeto de intercambio con otros países (Del Prado Merino y Nocete, 2011).

\section{Conclusiones}

A lo largo de la presente investigación se lograron evidenciar múltiples avances en materia de intercambio de información tributaria así como el papel activo que ha tenido Colombia en la suscripción de AIIT, tanto bilaterales como multilaterales, acompañado de la falta de experiencia reflejada en la parca regulación sobre las condiciones de intercambio, se concluye que en la legislación interna falta un largo camino por recorrer en cuanto a la consagración del secreto tributario, así como en la implementación de mecanismos directos de protección de los derechos fundamentales a la intimidad y al debido proceso de los contribuyentes, que deberán manifestarse en el respeto por la confidencialidad de la información y la consagración de los derechos de participación, que vinculen tanto a las autoridades administrativas locales como a las internacionales.

En este orden de ideas, se puede afirmar que la falta de regulación del secreto tribu- 
tario en la legislación interna ha aumentado exponencialmente la posibilidad de vulneración de los derechos fundamentales a la intimidad y el debido proceso, cuyo ejercicio, en el caso colombiano, se ha visto aplazado para la etapa de determinación del impuesto, dejando a los contribuyentes sin posibilidad de intervenir o ejercer su derecho de defensa durante el procedimiento de recaudo y transmisión de la información.

No obstante, a pesar de que en el presente estudio no se profundizó sobre cuál debe ser el contenido mínimo y el alcance del secreto tributario en Colombia, se evidencia una necesidad de incluir esta regulación a la legislación interna y se extiende una invitación para que futuros estudios se ocupen de determinar cuál debe ser el contenido de este derecho, al amparo de la supremacía constitucional de los derechos fundamentales de los contribuyentes, garantizando su debida protección ante los numerosos compromisos asumidos por el Gobierno de Colombia. 


\section{Referencias}

Arrieta, J. (1998). Cesión, intercambio y protección de la información tributaria y de los datos automatizados: la incidencia de la informática en el contribuyente. Revista Técnica Tributaria, 43(35). Recuperado de https:// dialnet.unirioja.es/servlet/articulo?codigo $=2834925$

Bodansky, D. (1999). The legitimacy of international governance: a coming challenge for international environmental law. American Journal of International Law, 93(3), 596-624. Recuperado de http://www.jstor.org/ stable/2555262?seq=1\#page_scan_tab_contents

Calderón, J. (2001). Tendencias actuales en materia de intercambio de información entre administraciones tributarias. Crónica Tributaria, 99, 25-40.

Calderón, J. (2009). El derecho de los contribuyentes al secreto tributario. En L. Bello (Ed.). La Coruña: NETBIBLO. Recuperado de http://ruc.udc.es/bitstream/2183/11858/2/9788497454476.pdf

Calderón, J. (2012). La asistencia mutua e intercambio de información en materia tributaria. En Convenios fiscales internacionales y fiscalidad de la Unión Europea. Valencia: Ciss.

Cockfield, A., y Macarthur, C. (2015). Country by country reporting and commercial confidentiality. Canadian Tax Journal,63(3), 627-660. Recuperado de file:///C:/Users/Tatiana/Downloads/15ctj3_All_documents_Public.pdf

Collado, M., Moreno, S., y Carreras, O. (2012). Estudios sobre el fraude fiscal e intercambio de información tributaria. Atelier Libros. Recuperado de https://books.google.com/books?id=xpMHueCSEGIC\&pgis=1

Del Prado, M., y Nocete, F. (2011). El intercambio de información tributaria en el derecho internacional europeo y español 6(6).

Marulanda, H. (2013). La competencia fiscal perniciosa entre Estados. Centro de Estudios Tributarios de Antioquia-CETA-.

Mosquera, I. (2016). Legitimidad y protección de derechos en el intercambio de información: la perspectiva del contribuyente. En Jornadas Colombianas de Derecho Tributario, Derecho Aduanero y Comercio Exterior. Bogotá: Instituto Colombiano de Derecho Tributario.

Oberson, X. (2015). International exchange of information in tax matters, global towards transparency. Cheltenham. Recuperado de https://play.google.com/books/reader?printsec=frontcover\&output=reader\&id=nd4WC QAAQBAJ\&pg=GBS.PR3

OCDE. (2002). Agreement on exchange of information on tax matters. Recuperado de http://www.oecd.org/tax/ exchange-of-tax-information/2082215.pdf

OCDE. (2006). Manual para la aplicación de las disposiciones relativas al intercambio de información con fines tributario.

OCDE. (2010). Modelo de convenio tributario sobre la renta y sobre el patrimonio. París: Instituto de Estudios Fiscales.

OCDE. (2011). Convención sobre asistencia administrativa mutua en materia tributaria. Estrasburgo. Recuperado de http://www.oecd.org/tax/exchange-of-tax-information/48094024.pdf

Pastrana, E. (2005). El principio de la no-reciprocidad: entre el deber ser y su regulación jurídica en el marco de las relaciones económicas internacionales y de cooperación. Papel Político, 17, 67-117. Recuperado de http:// www.redalyc.org/articulo.oa?id=77720407003

Santamaría, J. (1985). Sobre derecho a la intimidad, secretos y otras cuestiones innombrables. Revista Española de Derecho Constitucional, (5), 159-180. Recuperado de https://dialnet.unirioja.es/descarga/articulo/242179.pdf 